\title{
Right Ventricular Free Wall
}

National Cancer Institute

\section{Source}

National Cancer Institute. Right Ventricular Free Wall. NCI Thesaurus. Code C127647.

The lateral segment of the right ventricular wall, excluding the anterior and inferior right ventricular wall. 